\title{
Safety profile of drugs used in the treatment of osteoporosis: a systematical review of the literature*
}

\author{
${ }^{*}$ On behalf of The Italian Society of Osteoporosis, Mineral Metabolism, \\ and Skeletal Diseases (SIOMMMS); \\ ${ }^{\star}$ Endorsed by the Italian Society of Rheumatology (SIR);
}

\author{
M. Varenna ${ }^{1}$, F. Bertoldo², M. Di Monaco ${ }^{3}$, A. Giusti ${ }^{4}$, G. Martini ${ }^{5}$, M. Rossini ${ }^{6}$ \\ ${ }^{1}$ Bone Diseases Unit, Department of Rheumatology, Gaetano Pini Institute, Milan; \\ ${ }^{2}$ Department of Biomedical and Surgical Sciences, Unit of Diseases of Mineral Metabolism and the \\ Bone, University of Verona, Verona; ${ }^{3}$ Osteoporosis Research Center, Division of Physical Medicine and \\ Rehabilitation, San Camillo Hospital, Torino; ${ }^{4}$ Bone Clinic, Department of Geriatrics and Musculoskeletal \\ Sciences, E.O. Galliera Hospital, Genova; ${ }^{5}$ Department of Medical, Surgical and Neurological Sciences \\ University of Siena, Siena; ${ }^{6}$ Rheumatology Section, Department of Medicine, University of Verona, Verona, Italy
}

\section{SUMMARY}

The range of osteoporosis treatments is increasingly large and, like any disease, the pharmacological management of patients should involve a risk/benefit evaluation to attain the greatest reduction in risk of fracture with the lowest incidence of adverse events. The aim of this review is to critically appraise the literature about the safety issues of the main pharmacological treatments of osteoporosis. This document is the result of a consensus of experts based on a systematic review of regulatory documents, randomized controlled trials, metaanalyses, pharmacovigilance surveys and case series related to possible adverse drug reactions to osteoporosis treatment with calcium and vitamin D supplements, bisphosphonates, strontium ranelate, selective estrogen receptor modulators, denosumab, and teriparatide. As expected, randomized controlled trials showed only the most common adverse events due to the samples size and the short observation time. Case series and observational studies are able to provide data about uncommon side effects, but in some cases a sure cause-effect relationship needs still to be confirmed. Consistently with methodological limitations, the newer drugs have a tolerance profile that has not been fully explored yet. Osteoporosis treatments showed an overall good tolerance profile with rare serious adverse events that, however, must be well known by the clinician who prescribes these drugs. The concern about possible adverse events should be weighed against the reduction of morbidity and mortality associated with a significant fracture risk reduction.

Key words: Osteoporosis, Treatment, Pharmacology, Side effects.

Reumatismo, 2013; 65 (4): 143-166

\section{INTRODUCTION}

U ntil a few years ago physician's decisions in drug prescription were only based on personal knowledge and experience, but nowadays a therapeutic prescription should be supported by clinical evidences from the scientific literature. This approach is even more strictly required when the therapeutic goal is the prevention of a clinical event related to a chronic disease. In this situation the therapeutic strategy could be extremely extended in time and a single physician's experience could not obtain a good overlap of the prescribed therapy to the already obtained or possibly achievable results.

In this area, therapeutic decisions on osteoporosis (OP) treatment can be even more difficult: even if a number of drugs with different mechanisms of action has been made available in the last years, data about direct comparisons of efficacy between various therapeutic options are still lacking. Moreover, although a complete evaluation of the safety profile of drugs prescribed in elderly is required due to frequent comorbidities and concurrent treatments, regis-
Corresponding author: Massimo Varenna Bone Diseases Unit Department of Rheumatology Gaetano Pini Institute, Milan, Italy E-mail: varenna@gpini.it 
tration trials have limited durations up to 3 years, while therapeutic strategies targeted to fracture prevention should be extremely longer.

In the absence of evidences on long-term safety from clinical trials, data from medical literature on this issue are derived from observational post-marketing studies. However it could be extremely difficult to extrapolate the safety profile of the best therapeutic choice from these studies because of their low reliability related to the study design. Moreover, the lack or underutilization of national and international registries where drug-related adverse events are collected, does not allow a correct knowledge of the real incidence of these events. A further source of confusion about long-term safety of drugs can be provided by some marketing strategies of pharmaceutical industries, which tend to highlight side effects of drugs aiming to influence drug prescription to their advantage.

With the aim of clarifying these issues, a group of experts has been requested by the Italian Society of Osteoporosis, Mineral Metabolism, and Skeletal Diseases (SIOMMMS) to review all the recent literature on this topic, in order to release a document which could provide the physician with the most objective evaluation of the safety profile of available drugs for the prevention of fragility fractures.

\section{CALCIUM}

An insufficient calcium intake with a resulting negative calcium balance can lead to a secondary hyperparathyroidism, which can stimulate bone turnover and induce an increased bone loss. In subjects with a reduced calcium intake, calcium supplementation (with or without associated vitamin D) showed an anti-fracture efficacy especially in the elderly and in patients on chronic treatment with corticosteroids. A supplementation with calcium has been systematically prescribed to patients enrolled in studies investigating the anti-fracture efficacy of other drugs.

\section{Calcium supplements and cardiovascular risk}

The association between calcium supplementation and the risk of cardiovascular events has been investigated in a number of observational studies and randomized controlled trials (RCT), with conflicting results. In most studies, including a large RCT on 36,000 women with a 7-year follow-up, no significant interactions were found (17). Conversely, in 3 studies a higher relative risk (RR) of cardiovascular events related to calcium supplementation was observed in women (8), men and women (9), or men but not women (10), while a single observational study showed a reduced risk (11) even after a 20-year follow-up (12). A recent study showed an increased overall and cardiovascular mortality related to calcium supplementation only in women with a high intake of calcium from diet $(>1400$ $\mathrm{mg}$ /day), which could slightly increase the risk of death by itself (13). Systematic reviews and meta-analyses yielded conflicting results: a non significant modification of cardiovascular risk was found (14-17) as well as a $30 \%$ increase of myocardial infarction risk, without consistent variations of the risk of other events such as stroke, sudden death, or a combination of stroke, myocardial infarction and sudden death (18). A supplementation with calcium combined with vitamin $\mathrm{D}$, which is usually recommended (19-21) and prescribed in clinical practice (22), was shown to reduce the mortality from all causes (23), while in other studies was associated with an increased risk of cardio-vascular events (24). Not even the pathophysiological approach contributed to dispel the doubts: calcium supplements were related to a risk factors improvement $(16,25)$ as well as to potential adverse effects, like an increase in vascular calcifications (26) which however was not confirmed in other studies (27). In conclusion, available data do not provide clear evidences (28). This uncertainty is also related to methodological limitations of the available studies (29), such as those concerning data collection (often self-reported and not confirmed by blinded observers) from trials designed with different 
aims (7), results derived from sub-groups analyses (24), interferences with a concurrent assumption of calcium from diet or from other self-prescribed supplements (13), the reduced adherence to the therapy (30), the concomitant assumption of different dosages of vitamin D (30), the assumption of calcium supplements near the meals or in different moments of the day with possible variations in serum calcium levels (13), and the incomplete assessment of concomitant cardiovascular risk factors.

\section{Calcium supplements and nephrolithiasis risk}

Beside a certain protective effect of calcium from diet, calcium supplements show equivocal effects on nephrolithiasis risk. An increased risk of nephrolithiasis is mainly supported by a large observational study on more than 91,000 women with a 12-year follow-up (31) and by the Women's Health Initiative, a RCT on more than 36,000 women with a follow-up of 7 years (32). In the first study the RR of nephrolithiasis was 1.20 (CI 95\% 1.01-1.41), in the second one 1.17 (CI 95\% 1.02-1.34) with a moderate increase of absolute risk ( 2 cases per 10.000 person-years). On the contrary, 2 RCTs did not show an increased risk of nephrolithiasis $(5,33)$, as well as a number of observational studies on about 45,000 men $(34,35), 96,000$ young women (36) and 78,000 women after menopause (37). A recent systematic review did not show an increased risk of nephrolithiasis in subjects with OP treated with calcium supplements (38).

Also on these issues the literature shows important limitations, largely similar to those described for cardiovascular risk. As the protective effect of calcium from diet is ascribed to a reduced absorption of oxalate in the digestive tract, it could be convenient to take calcium supplements with meals, especially if oxalate-rich $(31,37)$.

\section{Summary of evidences}

Data about the association between calcium supplementation and cardiovascular or nephrolithiasis risk are not conclusive.

For prudential reasons, to achieve the cal- cium intake required for osteoporosis prevention and treatment, it should be recommended to:

- always estimate the calcium needed by every single patient before any prescription;

- try to achieve the adequate calcium intake from diet only;

- prescribe calcium supplements only when a diet modification is not sufficient, advising the patient to take them during meals, and at the minimal dose required to meet patient's requirement.

\section{VITAMIN D}

Deficits of vitamin D with a lower extent than those causing rickets and osteomalacia are still responsible for a reduced absorption of calcium in the intestinal tract and may represent a pathogenic way of OP, primarily in the elderly. In the last years a number of studies suggested a possible protective role of vitamin $\mathrm{D}$ and its metabolites in the pathogenesis of many extra-skeletal diseases, such as muscle, cardiovascular, autoimmune and neoplastic diseases.

\section{High doses of vitamin $D$}

The administration of vitamin D at high doses once a year in subjects not deficient was associated with an increased risk of falls and fractures. In a RCT on 2256 women treated with colecalciferol 500,000 IU per os for 3-5 years, the risk of falls (RR 1.15 ; $95 \%$ CI $1.02-1.30, \mathrm{P}=0.03)$ and fractures (RR 1.26; 95\% CI 1-1.59, $\mathrm{P}=0.047$ ) was higher in the treatment group than in the placebo group (39). A previous RCT on 9,440 subjects treated for 3 years with 300,000 IU of intramuscular vitamin D2 had shown a significant increase of risk only for specific types of fractures or in subgroups, without a significantly increased risk of falls (40). Both these studies have relevant methodological limitations among whom the main is, according to the authors (41), the inclusion of subjects with basal 25OH-vitamin D levels in the physiological range. A recent RCT investigating the effects of a supplementation with 
colecalciferol 150,000 IU every 3 months in subjects not deficient did not show any negative effect on the risk of falls and/or fractures (42). Vice versa, a previous RCT demonstrated favorable effects on falls and fractures of the administration of 100,000 IU of colecalciferol every 4 months for 5 years in 2686 subjects with unknown basal 25OH-vitamin D levels (43). Doses of colecalciferol higher than 600,00 IU were associated with increased levels of markers of bone resorption (44), while this association was not significant from a clinical point of view for boluses of 300,000 IU and absent for doses of 100,000 IU (45). Monitoring serum 25OH-vitamin D levels during supplementation is suggested only for high doses (>1000 IU/day) or when concomitant diseases can induce extremely elevated serum levels of vitamin D (granulomatosis) or enhance the consequences (primary hyperparathyroidism) (46).

\section{Vitamin D metabolites}

The use of vitamin D metabolites hydroxylated in position 1 (calcitriol and alfacalcidol) is associated with a significantly increased risk of hypercalcemia and hypercalciuria. This effect is well known and documented and it can be easily explained by an overcoming of the metabolic step that is an endogenous regulator of calcitriol synthesis $(47,48)$. However, serious consequences of hypercalcemia are infrequent (49). If the vitamin D metabolite hydroxylated in position 25 (calcifediol) is prescribed, it should be taken into account that doses in micrograms $(\mu \mathrm{g})$ or in IU did not match with those of colecalciferol. It has been recently suggested that $1 \mu \mathrm{g}$ (40 IU) of calcifediol equals 4-5 $\mu \mathrm{g}$ of colecalciferol (50), but more data are requested in different populations of patients with a long follow-up to exactly define the conversion factor between the two molecules.

\section{Summary of evidences}

Possible adverse effects related to doses of vitamin D higher than or equal to 300,000 IU, administrated once a year in subjects not deficient, have been reported.

To maintain an adequate vitamin D status, the use of fractionated doses such as daily, weekly or monthly doses is to be preferred. High doses of vitamin D to be taken in a few weeks are currently recommended in deficient subjects to correct the deficit.

A periodic check of serum $25 \mathrm{OH}$-vitamin $\mathrm{D}$ levels (e.g. every 2 years) should be performed in subjects supplemented with more than $1000 \mathrm{IU} /$ day. Checks should be more frequent in subjects with granulomatosis or primary hyperparathyroidism.

The highest safe dose in long-term treatments is $4000 \mathrm{IU} /$ day.

During pregnancy, when supplementation is indicated, boluses (single doses higher than 25,000 IU) have to be avoided.

Vitamin D metabolites hydroxylated in position 1 (calcitriol and alfacalcidol) can cause hypercalcemia and hypercalciuria and their administration is not recommended in osteoporosis treatment.

\section{BISPHOSPHONATES}

Pharmacokinetics of bisphosphonates (BP), which are characterized by a high affinity for bone, can explain their overall good tolerability. The low intestinal absorption (less than 1\%) even under the best conditions, such as fasting and in association with a large amount of water, causes the achievement of low plasma levels after oral administration. Even if serum peaks can be higher with parenteral administration, they are however transient and shortterm. Serum levels of BP quickly decrease due to fast adhesion to bone surface (about $50 \%$ ); the remaining amount is excreted by the kidney, through glomerular filtration and proximal tubular excretion (51). Skeletal retention of BP is instead extremely prolonged, although it varies depending on bone affinity of the different types of BP. Therefore biologic half-life of BP is long, despite their short serum half-life. A part of the amount released from skeleton can adhere to bone again, while the remainder is excreted by the kidney. Small amounts of BP have been documented in body fluids up to 8 years after the treatment was stopped $(52,53)$. This finding can justify 
caution in BP use in fertile women, even if an association with fetal malformations has not yet been demonstrated in humans (54), but possible interferences on fetal development were observed in animal models.

\section{Acute phase response}

Acute phase response (APR) is a transient flu-like syndrome, usually lasting 2-3 days, characterized by fever, myalgias and/or arthralgias, and malaise and which develops in approximately $30 \%$ of patients after the first i.v. administration of amino-BP (nBP) (i.e. pamidronate, zoledronate, neridronate and ibandronate) (55). Sometimes gastrointestinal manifestations (abdominal pain, nausea, vomiting) or ocular inflammations can occur (56). Despite being rare, APR has been reported also after high doses of oral nBP (ibandronate) (57). It is associated with a rapid reduction of circulating lymphocytes and with an increase of serum levels of $\mathrm{C}$ reactive protein (55) and proinflammatory cytokines, such as tumor necrosis factors, IL-6 and Interferon- $\gamma$ (58$60)$, which is the reason why it is called APR. The rapid overproduction of cytokines is related to $\gamma \delta$ T lymphocytes activation by metabolites of the mevalonate pathway, which accumulate after pharnesil-pyrophosphate-synthase inhibition by BP phagocytosed by monocytes (61-63). Serum levels of circulating $\gamma \delta \mathrm{T}$ lymphocytes are predictive of APR (64) and this observation can explain why this adverse effect is more frequent in young patients, who have a higher number of circulating $\gamma \delta$ T lymphocytes. APR does not develop or it is strongly attenuated after further infusions of $\mathrm{nBF}$ (51). This is probably related to a reduction in circulating $\gamma \delta \mathrm{T}$ lymphocytes over time, which has been observed after the first administration of i.v. nBP, especially when associated with an APR (65). It is unknown whether $\gamma \delta \mathrm{T}$ lymphocytes reduction can be associated with clinically significant immunological effects, either negative or positive, even because it is not clear whether it represents a reduced availability or chronic tissue activation. APR after zoledronate infusion seems to be also associated with a long-term reduction of circulating levels of other lymphocytes subpopulations and eosinophils (66).

APR can be prevented or managed with paracetamol or NSAIDs (67), but not with statins $(68,69)$ despite their use could be hypothesized with the aim to upstream inhibit mevalonate pathway and consequently reduce metabolites which accumulate after nBP administration (70). Vitamin D deficiency should be also prevented before $\mathrm{nBP}$ administration, since it is reported to enhance the risk of APR occurrence (71).

\section{Gastrointestinal side effects}

Gastrointestinal side effects, mostly of the upper tract, or even only concern of them, are the most frequent cause of reduced compliance or interruption of treatment with oral $\mathrm{nBP}$, also considering age and comorbidities of treated patients who are possibly affected by gastrointestinal diseases (72). These side effects can be partially prevented by instructing patient to take the medication with a large amount of water and without lying down for at least $30 \mathrm{~min}$ utes after taking the drug (73). Moreover the availability of weekly or monthly formulations strongly reduced the frequency of gastrointestinal adverse events by decreasing the probability of repeated stresses to gastro-esophageal mucosa (74-79). These side effects have never been reported after parenteral administration of BP.

A study based on a large English database of clinical prescriptions reported a doubled incidence of esophageal cancer related to oral nBP use for at least 5 years (80), but this finding was not confirmed by a further analysis performed on the same database (81). Even in patients with Barrett's esophagus treated with oral $\mathrm{nBP}$ an increased risk of esophageal adenocarcinoma was not observed (82). In 2012 the US Food and Drug Administration declared that, based on current knowledge, no definitive conclusions can be drawn about the relationship between oral BF and esophageal cancer. A recent meta-analysis of observational studies did not find any evidence about the association between oral BP and esophageal adenocarcinoma (83). 
Even if the tolerability profile and the gastrointestinal risk are overall acceptable, further investigations are required when dysphagia and retrosternal or epigastric pain are observed in conjunction with oral $\mathrm{BP}$ administration.

\section{Hypocalcemia}

A transient hypocalcemia with consequent hypocalciuria and secondary hyperparathyroidism is expected because BP are strong inhibitors of osteoclastic resorption, which contributes to physiological release of calcium from bone to bloodstream. However hypocalcemia is usually asymptomatic in the absence of other predisposing conditions, such as a reduced calcium intake and/or low vitamin D levels, hypoparathyroidism or renal failure.

\section{Renal failure}

Based on their pharmacokinetics, BP are known to be excreted by the kidney, therefore prescription of these drugs is not recommended when creatinine clearance is lower than $30 \mathrm{~mL} / \mathrm{min}$ (84). Renal failure was an exclusion criterion in pivotal trials on BP. However, a number of patients with mild renal failure and without alterations of phosphocalcic metabolism were included in trials, so allowing verifying the good tolerability of $\mathrm{BP}$ also in these conditions (84-86).

Therefore, even if specific studies on patients with chronic renal diseases are lacking, BP use is allowed also in these conditions but a low dose and/or a reduced frequency of administration are needed (86). In patients with a renal transplantation, even in the absence of evidences of anti-fracture efficacy, BP are usually recommended to prevent bone loss (87-89). It is however noteworthy that in chronic renal failure metabolic bone diseases other than OP can be observed and intravenous BP use can induce an extreme suppression of bone turnover (adynamic bone) (88).

It is also well known that a quick infusion of high doses of BP can induce acute renal failure (90). In a small subgroup of patients with postmenopausal OP, a transient increase of creatinine levels was ob- served 10 days after an infusion of zoledronate lasting more than 15 minutes (91). It is therefore recommended that patients treated with intravenous BP are properly hydrated and do not take other treatments potentially nephrotoxic.

Because direct comparisons between different intravenous BP do not exist, it is not known whether ibandronate has a safety renal profile different from zoledronate (91).

Oral BP use at registered doses for the treatment of postmenopausal OP does not pose risks in terms of renal function.

\section{Musculoskeletal pain}

Even if the association with BP use is still discussed, the onset or a worsening of musculoskeletal pain following alendronate, risedronate or zoledronate administration have been reported, but are usually reversible after treatment interruption (92-94). No convincing physiological explanation has been conceived yet.

\section{Ocular inflammation}

Cases of iritis, episcleritis and conjunctivitis have been reported after BP use, especially for intravenous administration and with an incidence up to $1 \%$ (95-97). This side effect does not seem to be exclusive of the most recent BP, having been reported also with first generation BP (98). These adverse events can be managed with local corticosteroids. In the most severe cases BP treatment should be interrupted and patients should be discouraged from reintroducing these drugs (99).

\section{Cutaneous manifestations}

Rash, itching and urticaria have been reported with BP use, but rarely (100). They do not seem to be a class effect, because these cutaneous reactions can disappear changing BP.

\section{Mucositis and oral mucosa lesions}

Rarely, mucositis and oral mucosa lesions have been described but they do not seem to correlate with osteonecrosis of the jaw (ONJ) risk (101).

Usually they were related to an incorrect 
modality of drug intake and recovered after treatment interruption or simply complying with drug instructions.

\section{Hepatitis}

A few cases of transient hepatitis, documented by liver biopsy, have been reported after alendronate (102) or risedronate (103) treatment for months or years. They recovered after treatment interruption.

\section{Cardiovascular risk}

Patients treated with BP usually have an increased cardiovascular risk related to age, comorbidities and OP itself $(104,105)$. In a pivotal study on zoledronic acid a higher incidence of atrial fibrillation was observed as severe adverse event in the treatment group than in the placebo group $(1.3 \% \mathrm{vs}$ $0.5 \%$, respectively) (106). This finding was not confirmed in a further trial $(1.1 \%$ incidence in the treatment group vs $1.3 \%$ in the placebo group) (107). Post-hoc analyses from the main trials on alendronate, risedronate and ibandronate, which involved about 30,000 patients, did not confirm the association between BP use and risk of atrial fibrillation (108-110). In 2011 the Food and Drug Administration concluded that there were not enough reasons to suspect that OP treatment with BP could induce atrial fibrillation.

On the contrary, a part of mortality reduction which was observed after zoledronate treatment in patients with femoral fractures was ascribed to a reduced incidence of arrhythmias (111). Moreover, a reduced risk of myocardial infarction was recently observed during BP treatment in patients affected by Rheumatoid Arthritis (112).

\section{Osteonecrosis of the jaw}

Osteonecrosis of the jaw (ONJ) associated to $\mathrm{nBP}$ treatment is defined for diagnostic purposes as the presence of an area of exposed bone in the oral cavity that does not heal within 8 weeks of appropriate treatment, in a patient who currently receives or has been exposed to a BP and has not had radiation therapy to the craniofacial region. This definition proposed by the American Society for Bone and Mineral
Research (ASBMR) Task Force (113) has been implemented in 2009 by the Italian Ministry of Health. Other clinical signs or symptoms can arouse suspicion of an ONJ but do not permit a definite diagnosis (113). Four clinical stages have been defined, with a stage 0 .

This staging has been recently modified (114) and it is currently undergoing a further revaluation (115). From a pathological point of view it is a chronic osteomyelitis usually caused by germs of the oral flora, in particular Actinomices. Its pathogenesis has not yet been defined and a number of molecular and genetic factors have been postulated.

Certainly bone turnover suppression and bacterial contamination play a key role (116). In patients with OP the main risk factors for $\mathrm{ONJ}$ are a prolonged treatment with oral BP ( $>3$ years for alendronate), uncontrolled diabetes, a treatment with corticosteroids or immunosuppressive agents, and an excessive consumption of alcohol or smoking.

Among local risk factors, tooth extraction, dental and periodontal disease, and incongruous dental prostheses are the main predisposing factors, while implant-prosthetic procedures and dental-alveolar elective surgery are surely less relevant risk factors $(117,118)$. Because the frequency of ONJ in patients with OP is extremely low, these risk factors are borrowed from a number of case studies on ONJ in patients with cancer. Therefore the level of evidence and prediction of these factors is relatively low (119). ONJ in patients with OP is a rare adverse event. No reliable epidemiological data about ONJ are available in this clinical setting and prospective data are lacking.

The uncertainty is even higher because cases of ONJ have been described also in a population of subjects who have never been treated with BP (120). The first evaluations of incidence made an estimate of 1 case for 10,000-100,000 person/years (113). An Australian survey assessed an incidence between $0.01 \%$ and $0.04 \%$, which increased to $0.09-0.34 \%$ in patients who underwent tooth extraction (121). These data have been recently confirmed by some 
cohort studies $(0.02 \%)$ (122). The estimated prevalence of $\mathrm{ONJ}$ in $\mathrm{OP}$ varies from $0.02 \%$ to $1 \%$ (123).

The most reliable epidemiological data are related to the use of alendronate due to its widespread use (120), while the real incidence and prevalence of $\mathrm{ONJ}$ in patients treated with i.v. zoledronate $5 \mathrm{mg} /$ year or ibandronate $4 \mathrm{mg}$ every 3 months can hardly be assessed epidemiologically.

In Italy it is extremely high the concern of dentists, who are often unwilling to perform invasive procedures, above all extractions and dental implants, in patients who have been treated even for a short time with BP for OP or, alternatively, they suggest prolonged drug interruptions before dental works. In 2009 the SIOMMMS in collaboration with the National Association of Italian Dentists (ANDI) produced a consensus document on the prevention of ONJ in patients with OP (www.SIOMMMS.it) which was endorsed by the main Italian scientific societies involved in OP management (SIR, SIOT, FADOI, SIRM, SIMFER e CROI). Based on more recent data about ONJ, an update of these recommendations may be useful.

It is interesting to point out that many recommendations based on international literature and reported in guidelines (such as national guidelines by SIOMMMS) are supported by a low level of evidence but by a high strength of recommendation based on experts opinion.

The Ministry of Health produced some recommendations for ONJ prevention in patients with cancer. Recently a document on ONJ related to BP use in patients with cancer and in patients with OP was released by the Italian Society of Maxillo-Facial Surgery (SICMF) and the Italian Society of Oral Pathology and Medicine (SIPMO) (124).

Atypical femoral subtrochanteric/diaphyseal fractures

Atypical femoral subtrochanteric/diaphyseal (ST/DF) fractures are an uncommon adverse event that at the beginning was described in patients subjected to longterm therapy with BP $(125,126)$. These fractures were defined as atypical because of their clinical and radiological features, which are different from those of classical or typical ST/DF fractures in elderly with OP $(125,126)$. Atypical femoral ST/DF fractures develop spontaneously or after a minimal trauma anywhere in the femur from just below the lesser trochanter to above the supracondylar line.

They can be complete fractures from lateral to medial cortical or incomplete fractures that involve only the lateral cortex (stress fractures). Clinically, a patient can complain about a discomfort/pain in the thigh or hip - that increases with load -days/ weeks before fracture develops (or is diagnosed). Radiologically atypical fractures are characterized by a transverse or short oblique fracture line and are noncomminuted, while classical ST/DF osteoporotic fractures show a long oblique, longitudinal or sometimes spiral fracture configuration (126).

In a number of case-reports a thickening of the medial and lateral cortices of the femoral diaphysis and a localized periosteal reaction of the lateral cortex were described (126). Both these features however were not systematically observed and therefore they are currently not considered among major criteria for radiological definition and diagnosis of atypical ST/DF fractures, according to the ASBMR report recently published (125). Finally, a significant delay in fracture healing has been frequently described (126).

Even if these fractures have been mainly described as a complication of BP therapy, atypical fractures indistinguishable from those observed in patients treated with BP were found also in subjects with hypophosphatasia, in patients treated with corticosteroids or denosumab, or in subjects never exposed to BP (125-129).

Epidemiological data about prevalence and incidence of atypical ST/DF fractures in patients treated with BP are scarce and mostly derived from retrospective studies. The main limitation of these studies is related to the lack of an X-rays observation without a direct assessment of the radiological features of atypical fractures (short 
oblique noncomminuted fracture configuration), which distinguish atypical ST/DF fractures from typical ones in elderly osteoporotic patients. Only the few studies in which the direct observation of X-rays allowed the ascertainment of radiological features of atypical fractures enabled us to define epidemiology and risk factors (130141).

Atypical femoral fractures related to $\mathrm{BP}$ therapy seem to represent the $0.4-0.6 \%$ of all femoral fractures $(131,135)$. The incidence of atypical fractures in patients treated with BP is extremely variable from an estimate of 2 cases per 100,000 personyears to 113 cases per 100,000 personyears (132-141).

This high variability is related to a number of factors: the inclusion or not of ASBMR minor criteria (125) in radiological definition of atypical fracture $(138,142)$, the calendar year in which prevalence was estimated (137), and the duration of BP treatment $(132,134)$. In the general population (never treated with BP) the incidence of atypical ST/FD fractures is estimated from 0.3 to 2 cases per 100,000 person-years (133) with a high variability related to age (16 cases per 100,000 person-years in subjects aged $>65$ ).

Case-control studies published in the last 4-5 years evaluated the significance of the association between BP use and atypical ST/DF fractures and estimated the risk to develop an atypical ST/DF fracture during BP treatment. Most of these studies (130$132,137,138,143-146)$ but one (136) confirmed an increased risk of atypical ST/ $\mathrm{DF}$ fracture in patients treated with $\mathrm{BP}$ and pointed out that the risk increases with the duration of exposure to BP. One of these studies also showed that the BP discontinuation is associated to a risk reduction, even after a short time (132). Finally, two casecontrol studies identified other potential risk factors related to atypical femoral ST/ DF fractures $(130,131)$ such as corticosteroids therapy, hypovitaminosis $\mathrm{D}$, previous osteoporotic fractures, active rheumatoid arthritis.

The most likely hypothesis about pathogenesis of atypical femoral ST/DF fractures is represented by an excessive suppression of bone turnover in patients extremely susceptible to the antiresorptive effect of BP $(125,126,147-150)$. This higher susceptibility could be related to intrinsic factors (vulnerable osteoclasts, reduced bone formation ability) or to external factors, most likely related to other drugs (corticosteroids, proton pump inhibitors) or diseases (rheumatoid arthritis, hypovitaminosis D). Even if this hypothesis is supported by the first studies investigating atypical ST/DF fractures pathology $(149,150)$, it was not confirmed in other studies who found in bone biopsies of patients with atypical ST/ DF fractures and treated with BP a normal, not suppressed bone turnover (126).

No guidelines are available that define an evidence-based approach to prevent atypical femoral ST/DF BP-related fractures. On the contrary it has been clearly demonstrated that benefits derived from BP treatment are higher than potential risks (151). With the aim to minimize atypical fracture risk in patients subjected to long-term BP treatment, it has been proposed to consider some periods of drug holiday, after a thorough evaluation of the risk/benefit ratio and concomitantly with a correction/ monitoring of other possible risk factors for atypical fractures (152-154).

\section{Summary of evidences}

The safety profile of BP is overall reassuring, also considering the long-term experience with these drugs and the lack of ascertained severe or life-threatening adverse events to date.

Acute phase response to amino-BP is limited to the first administrations, easy to prevent or manage and it does not seem to be associated with unwanted clinical consequences.

The availability of weekly or monthly oral formulations has improved the gastrointestinal tolerability and reduced the risk of side effects in this site, if the drug is taken correctly.

Intravenous BP use is not associated with a significant risk regarding renal function, provided an adequate hydration and when recommended doses and times of infusion 
are respected. If indicated, their use is possible, eventually with a dose adjustment, even in patients with a mild impairment of renal function.

Other side effects are uncommon and, even if their presence should be looked at and excluded, they do not seem to overall compromise the risk/benefit balance of BP treatment.

\section{Osteonecrosis of the jaw}

It is widely accepted that the best way of management of ONJ is prevention, which is mainly based on risk factors control.

In patient who are starting a treatment with BP for OP, a dental evaluation with an eventual cleaning up before therapy is not necessary. Patients should be only advised to keep a good oral hygiene, as in general population, especially if their oral hygiene is not satisfactory.

When invasive dental procedures are required, starting $\mathrm{BP}$ treatment could be eventually delayed after dental problem is recovered, or alternatively dental procedures could be performed in the first 6 months of BP therapy.

In subjects who have been treated with BP for OP for less than 3 years and without individual risk factors (diabetes, immunosuppression, corticosteroids, smoking) the risk of ONJ during invasive surgical procedures is extremely low and no specific cautions or conducts are required.

Based on epidemiological data, the unwilling of the dentist to perform invasive dental procedures (such as tooth extraction) in patients treated with $\mathrm{BP}$ or considering dental procedures alternative to $\mathrm{BP}$ treatment, in the absence of other documented risk factors, seems to be not justifiable. Sometimes the lack of dental treatment itself could represent a risk factor for ONJ.

For subjects treated with BP for more than 3 years (with a compliance $>80 \%$ ) it is recommended to keep a regular professional oral hygiene, as suggested for the general population. If an invasive dental procedure (tooth extraction) is required, many guidelines suggest the drop off of BP for a 3 months period and the reintroduction of the drug after surgical wound is healed. There is no evidence that this approach actually reduces ONJ risk considering the persistency of drug effect for a long time. For the same reason however BP discontinuance for a brief time (1-2 months) likely does not compromise the efficacy of OP treatment.

Recently some authors proposed to stop the drug after tooth extraction until local mucosa is healed. Prolonged discontinuations of the drug should be arranged between both dentist and BP prescriber.

In cases of invasive dental procedures (tooth extraction), especially if individual risk factors are present (diabetes, immunosuppression, corticosteroids, smoking, alcohol consumption) an adequate antibiotic prophylaxis is suggested (amoxicillin eventually combined to metronidazole, to be started a few days ( 2 to 5 ) before dental procedure and to be continued for at least 10-15 days after, until gingival mucosa healing). Antibiotic prophylaxis should be combined with a surgical procedure involving primary closure of the site of extraction with mucoperiosteal flaps.

There is no contraindication to perform dental implantations during BP treatment. In the literature only 12 cases of ONJ associated to implantation have been reported, with an estimate of risk of implant loss of $0.88 \%$. However a possible complication of implantation itself is perimplantitis, which can increase ONJ risk during $\mathrm{BP}$ treatment. It is therefore advisable that the patient complies with a strict oral hygiene program.

\section{Atypical femoral fractures}

Atypical femoral subtrochanteric/diaphyseal fractures are an uncommon complication of a prolonged exposure to BP, which however have been described also in patients never exposed to BP.

Based on available data, the risk/benefit balance of BP treatment in osteoporosis prevention clearly favors benefits.

With the aim to minimize atypical fracture risk in patients treated with $\mathrm{BP}$ it should be suggested to:

- consider some periods of drug holiday after a thorough evaluation of the risk/ benefit balance; 
- correct/monitor other possible risk factors for atypical fractures.

\section{STRONTIUM RANELATE}

Common side effects of strontium ranelate therapy are usually mild and transient. The most frequent side effects are nausea and diarrhea, which usually develop at the beginning of the treatment and tend to disappear after 3 months of therapy.

The hypothesis of an increased vascular risk came from a combined analysis of registration trials that showed in 5 years an increased annual incidence of venous thromboembolism in subjects treated compared to placebo $(0.9 \%$ vs $0.6 \%$; RR 1.4 ; 95\% CI: 1.0-2.0) (155).

A retrospective study on the United Kingdom General Practice Research Database (GPRD) (156) showed that women with OP have a higher risk of venous tromboembolism compared to women without $\mathrm{OP}$, regardless of the treatment (no therapy, strontium ranelate, alendronate). Similar results were reported in other studies $(157,158)$.

Recently a large prospective European study with a 3-year follow-up was published, that included 32,446 women among whom 12,046 were treated with strontium ranelate (159). The incidence of venous thromboembolism was 2.1 per 1,000 person-years, and 3 per 1,000 person-years in the subpopulation aged $>80$. It was therefore established that the drug was contraindicated in patients with previous or current venous thromboembolism and in cases of temporary or permanent immobilization. The opportunity to maintain the treatment in patients aged $>80$ and at risk of venous thromboembolism was deemed worthy to be reassessed (160).

Strontium ranelate administration has been associated with rare cases of severe allergic skin reactions, sometimes with systemic symptoms potentially fatal in the contest of Drug Rash with Eosinophilia and Systemic Symptoms (DRESS) syndrome or of the Stevens-Johnson syndrome (toxic epidermal necrolysis) (161-164).
The pathogenesis of these hypersensitivity syndromes is not clear since strontium is an element present in nature in human organisms and ranelate is poorly absorbed. Postmarketing experience on treated patients reports a number of cases lower than 20 per 570,000 person-years of exposure and this low incidence of reactions is probably the reason why no cases have been reported in clinical trials.

Even in the European observational study on more than 12,000 patients no skin reactions were recorded (159). In conclusion, strontium ranelate causes few non-skeletal effects both concerning vascular events and hypersensitivity reactions (165). However, considering the eventuality that these events may occur, in cases of skin reactions in the first 2 months of treatment drug needs to be stopped and not reintroduced (160).

Recently the Pharmacovigilance Risk Assessment Committee (PRAC), a European Medicines Agency (EMA) organism responsible for the safety evaluation and monitoring of human drugs, pointed out a possible association between the use of strontium ranelate and an increase of heart side effects, above all myocardial infarction. PRAC reanalyzed cardiac side effects in 7 studies on postmenopausal OP (3803 patients treated with strontium ranelate), 1 study on male OP (173 treated patients) and 2 studies on osteoarthritis (586 treated patients). In a pooled analysis of the studies on postmenopausal OP (7572 patients) an increased number of myocardial infarctions was observed in patients treated with strontium ranelate compared to placebo (1.7\% vs $1.1 \%$, OR: 1.6 ; 95\% CI: $1.06-$ 2.38), even if no differences in cardiovascular mortality and total mortality between the two groups were found. From studies on male OP and osteoarthritis, due to the small sample size and to the low frequency of events, no conclusions could be drawn. However it should be reported that in a post-marketing evaluation of $3,402,769$ person-years, from September 2004 to February 2013, no alarming signals of heart diseases were observed. Also in the aforementioned European observational 
study no cases of heart diseases related to therapy were reported and the observed incidence of myocardial infarction was 1.3 per 1000 person-years, lower than in clinical trials (159).

Regarding the possible pathogenesis of cardiac damage, some hypotheses have been proposed about the relationship between the calcium-like effect of strontium ranelate and ischemic heart disease and a possible effect on hemostasis, but these hypotheses still need to be demonstrated.

Based on studies to date considered, on April 25, 2013, the EMA's Committee for Medicinal Product for Human Use (CHMP) received PRAC observations and recommended that strontium ranelate should only be used for the treatment of severe OP in postmenopausal women at high risk for fracture and severe OP in men at increased risk for fracture (166). On this basis, the Italian Medicines Agency (AIFA) recently modified the prescription modalities of this drug, stating that it has to be prescribed only by a physician skilled in OP treatment and after filling out a therapy certification. Moreover, the treatment with strontium ranelate is contraindicated in patients with a history of thrombosis or thromboembolism, cardiovascular disease, cerebrovascular disease, or peripheral vascular disease. The same restrictions have to be applied to subjects at high risk for thrombosis or cardiovascular events, even in absence of a history of these events (167).

\section{Summary of evidences}

Strontium ranelate should be immediately interrupted in cases of skin reactions in the first months of treatment.

Strontium ranelate should not be prescribed to patients with:

- previous or current venous thromboembolism;

- temporary or permanent immobilization;

- uncontrolled hypertension and/or ischemic heart disease, obliterating arteriopathy of the lower limbs, and cerebrovascular diseases.

The treatment is also contraindicated in patients without a history of cardiovascular events, but with risk factors for them (hypertension, hyperlipidemia, diabetes, smoking).

\section{SELECTIVE ESTROGEN RECEPTOR MODULATORS}

Problems related to side effects of hormone replacement therapy (HRT) (168) stimulated pharmacological research to develop molecules that could keep the benefits of estrogen therapy reducing the incidence of adverse events, which are still contraindicating HRT for the prevention and treatment of postmenopausal OP and related fractures.

Major concerns regarding the founder of the class, raloxifene, which was introduced on the market in the second half of the 90s specifically indicated for postmenopausal OP prevention and treatment, are related to an increased risk of thrombotic and thromboembolic events associated to the treatment.

This association, already observed in the registration trial, is expressed by a RR of 3.1 (95\% CI: $1.5-6.2)$ for venous thrombosis and of 4.5 (1.1-19.5) for pulmonary thromboembolism (169). The incidence of these side effects is higher in the first 2 years of treatment, when the RR is higher than $6(6.6$; $95 \%$ CI $0.95-50.4)$, then progressively decreases in the following years (170). Overall the size of this side effect is approximately comparable to what is observed during HRT (171). The importance of this result needs also to be considered in the context of inclusion criteria of these studies, which excluded subjects with previous thromboembolic events. Moreover, as following studies confirmed, specific predisposing factors to these side effects cannot be identified (172). Finally, the causal relationship between raloxifene and thrombotic and thromboembolic events was confirmed by a meta-analysis of 9 studies including more than 24,000 patients, which showed a total increase of venous thrombosis and thromboembolism of $62 \%$ (OR 1.62; 1.25-2.09) (172).

Considering other possible side effects, in the RUTH study on 10,000 women with 
coronary heart disease or with risk factors for coronary heart disease and treated for more than 5 years with raloxifene, besides an increase of the incidence of thrombotic and thromboembolic events, there was a significant increase of deaths from stroke in subjects treated with raloxifene (hazard ratio 1.49 ; $95 \% \mathrm{CI}: 1.00-2.24)$, while the total number of strokes (fatal and not) was comparable to healthy subjects in the placebo group (173).

Further studies on the same population found that smoking was a risk factor for this side effect (174) and that a concomitant therapy with acetylsalicylic acid or other antiplatelet agents could not reduce the incidence of thrombotic and thromboembolic events (175). Even if the association between raloxifene and thromboembolic diseases was confirmed by all the studies on this issue, the employment of a composite assessment score which includes all the possible outcomes of HRT demonstrated that raloxifene shows an overall positive risk/benefit balance with a higher survival rate of treated patients compared to control population (176).

Finally, it should be noted that raloxifene is associated with other side effects which are clinically less relevant but still responsible for a higher discontinuation rate compared to placebo (177), such as leg cramps and a worsening of postmenopausal vasomotor instability (178). Therefore the overall data suggest that raloxifene should not be prescribed to subjects with previous thrombotic events and similarly it should be immediately stopped in subjects at higher risk for these events (prolonged immobilization). Also in patients with previous cerebrovascular events the drug should be used with caution.

Bazedoxifene, another selective estrogen receptor modulators (SERMs) recently introduced on the market, has not yet been investigated in long-term post-marketing observational studies in which the incidence of side effects in the general population can be assessed. Considering the possible side effects, from registration trials the safety profile of bazedoxifene seems to be similar to that of raloxifene regarding the incidence of thromboembolic diseases, leg cramps and vasomotor instability (179, 180). Also in this case a higher incidence of thromboembolic disease was observed in a population of postmenopausal women from whom subjects with previous thrombotic or thromboembolic events were excluded. In the extension studies at 5 (181) and 7 (182) years, bazedoxifene showed similar results to those observed in the first 3 years of treatment, with a higher incidence of thrombotic and thromboembolic events, vasomotor disturbances and leg cramps than in the placebo group.

\section{Summary of evidences}

Even if the overall effect on mortality prevention seems to be positive, SERMs cause an increased risk of thromboembolic events, especially in the first 2 years of treatment. On this basis, this drug should not be prescribed and the treatment should be stopped in situations of increased risk (i.e. prolonged immobility, bedridden patients). The concomitant therapy with antiplatelets agents does not seem to reduce the risk of thromboembolic events. Raloxifene also seems to increase the risk of stroke, especially in subjects at higher risk (older age, hypertension, diabetes, previous cardiovascular diseases, smoking, atrial fibrillation, left ventricular hypertrophy).

Bazedoxifene shows a safety profile very similar to that of raloxifene.

SERMs can induce a worsening of postmenopausal symptoms (leg cramps, vasomotor disturbances) especially at the beginning of the treatment.

\section{DENOSUMAB}

Notwithstanding the limitations related to its recent introduction on the market, all the published studies seem to allay fears of possible extra-skeletal effects of denosum$\mathrm{ab}$ (Dmab), due to a theoretical interference with immune response and inflammation. No reliable data demonstrating an increased incidence of neoplasms and infectious diseases in patients treated with this drug are available. 
To date reported side effects were concerning an increased incidence of adverse events shared with other osteoclasts inhibitors (BP), such as ONJ and atypical femoral fractures.

\section{Osteonecrosis of the jaw}

An association with ONJ was observed in Dmab registration trials. The pathogenesis of this side effect has not yet been clearly defined (as for nBP). Osteoclasts activity inhibition seems to be a basic pathogenetic step, even if the inhibition of the RANK/ RANKL pathway is assumed to interfere with the activity of macrophages, monocytes and dendritic cells, so promoting ostomyelitis development (183). There are some common aspects between ONJ related to BP and to Dmab.

Epidemiological data about ONJ related to Dmab therapy in postmenopausal OP or in other benign diseases of bone metabolism are scarce and not conclusive. They are limited to data deriving from RCTs. In phase II and phase III studies, where almost 15,000 patients with postmenopausal $\mathrm{OP}$ were treated, no cases of $\mathrm{ONJ}$ were reported.

In the 5-year extension of the FREEDOM trial only 2 cases of ONJ per 4550 patients with postmenopausal OP treated with Dmab $60 \mathrm{mg}$ every 6 months were identified. These 2 cases belonged to the switch arm from placebo (3 years) to Dmab (2 years). Both these cases ended in ONJ healing and one of the patients was given 2 more doses of Dmab (184). Maybe because pharmacokinetics of Dmab is different from that of BP, so that after Dmab interruption there is a quick restoration of bone turnover, cases of ONJ related to Dmab treatment (in patients with bone metastases) seem to have a faster recovery than patients treated with BP (40\% vs 29\%) and a higher proportion of patients $(60 \%$ with Dmab vs $43 \%$ with zoledronate) heals with conservative therapy only (185).

Atypical femoral subtrochanteric/diaphyseal fractures

Cases of atypical femoral ST/DF fractures, similar to those reported in patients treated with BP $(125,186)$, have been described in women with postmenopausal OP treated with Dmab $(187,188)$. Among patients enrolled in the extension phase of the FREEDOM trial (184) 2 cases of atypical fractures were reported (in 2 patients) (187). The time of exposure to Dmab when diagnosis of atypical ST/DF fracture was made was longer than 2 years and a half. Another case of ST/DF fracture with some features of atypical fractures was reported in a case-report published by Paparodis et al. (188). In this report, as highlighted by the authors, the radiological features of the fracture did not completely adhere to the definition criteria of atypical ST/DF fracture, since the fracture line (in this case incomplete) originated from the medial cortex and not from the lateral cortex, as requested by the ASBMR criteria (125). In the case-report by Paparodis et al., the ST/ DF fracture was diagnosed 5 months after the first subcutaneous injection of Dmab, following the onset of pain/discomfort in the thigh. The radiological features of the fracture and the brief exposure to Dmab treatment make highly unlikely the relationship between drug administration and the ST/DF fracture (188).

Based on data from the FREEDOM study (189), which enrolled almost 8000 women affected by postmenopausal OP, atypical femoral ST/DF fractures seem to be a rare event, with an estimated incidence from $\geq 1 / 10,000$ to $<1 / 1000$ person-years (190). However, also considering the few available data (recent introduction on the market, limited post-marketing surveillance), at the moment no reliable estimates of incidence can be made nor the magnitude of the risk of atypical fractures during Dmab therapy can be assessed.

\section{Summary of evidences}

Data about an increased incidence of ONJ related to Dmab therapy in postmenopausal OP are scarce, and the event seems to be very rare ( 2 cases/4450 patients).

Risk factors and pathogenesis of ONJ are not well assessed, but at the moment it seems reasonable in this regard to equate Dmab to BP for OP treatment. 
In the absence of guidelines or documents ad hoc with a high level of evidence, it seems necessary to adopt for Dmab the same cautions and safety measures recommended for $\mathrm{nBP}$ in OP treatment.

In cases of ONJ, pharmacokinetics of Dmab after interruption seems to allow a faster healing of ONJ, which often can occur with conservative therapy only.

Anecdotal cases of atypical femoral subtrochanteric/diaphyseal fractures have been described in postmenopausal women treated with Dmab.

The incidence of atypical fractures in patients treated with Dmab seems low (from $1 / 10,000$ to $1 / 1000)$. However, based on available data, no reliable estimates can be given.

Even if a cause-effect relationship is conceivable, to date the magnitude of the risk of an atypical femoral fracture during Dmab treatment cannot be assessed.

\section{TERIPARATIDE}

The administration of teriparatide (the active 1-34 fraction of parathyroid hormone) is associated with a transient increase of serum calcium levels (about $0.8 \mathrm{mg} / \mathrm{dL}$ ) with a peak after 4-6 $\mathrm{h}$ and a following reduction, until basal levels are reached before the following day administration. These serum calcium variations usually remain in the normal range, but only in $11 \%$ of cases a slight hypercalcemia was observed in pivotal trials. Repeated or persistent hypercalcemia suggest a reassessment of the diagnosis and eventually the reduction or interruption of calcium supplementation. A dose reduction of teriparatide is rarely necessary.

In some trials it was also observed an increase in calcium renal excretion (about 30 $\mathrm{mg}$ in 24 hours) without clinical manifestations. However it should be mentioned that patients with a history of hypercalciuria or nephrolithiasis in the previous 5 years were excluded from trials. In $3 \%$ of patients an increase of serum uric acid was also observed.

Even if these changes in laboratory are overall slight, Teriparatide should be avoided in patients with a history of nephrolithiasis or gout or, alternatively, serum and urinary levels of calcium and uric acid should be monitored $(191,192)$.

In clinical trials, usually in the first hours after teriparatide administration, dizziness $(9 \%)$ and leg cramps $(3 \%)(190,191)$, or a local skin reaction with a rash in the site of injection (164) have been reported with a higher frequency than placebo.

\section{Summary of evidences}

Safety profile of teriparatide is overall good. Monitoring serum calcium during treatment is however appropriate.

Absolute contraindications to teriparatide are: primary hyperparathyroidism, Paget's disease of bone, a previous radiation therapy of the skeleton and primary or metastatic bone neoplasms.

In the absence of definitive data, caution should be used about drug prescription in patients with active urolithiasis.

The possible occurrence of orthostatic hypotension and/or dizziness with drug administration should suggest caution (supine position for an adequate time) with the aim to avoid falls.

\section{CONCLUSIONS}

The global evidence emerging from this wide review of literature is that safety profile of drugs prescribed for the treatment of OP and the prevention of fragility fractures is very high.

Side effects are infrequent and severe adverse events are extremely rare. Due to this peculiar low incidence, for some of these side effects the main concern is to assess a certain causal link.

Risk monitoring in observational studies and a worldwide implementation of pharmacovigilance programs can allow, notwithstanding the inevitable methodological limitations, to draw more reliable conclusions about some characteristics of side effects, such as the real incidence, the cause/effect relationship and the correlation between the total dose and length of 
treatment and the risk of side effect occurrence.

At the same time, the assessment of these parameters in the real life could allow to get over some limitations of RCTs and to identify the risk factors predisposing to an adverse event. An adequate knowledge of these parameters is a prerequisite for identifying the risk/benefit profile of every drug, being known the efficacy of these treatments in reducing the incidence of fragility fractures.

Finally, this approach could also help to identify the treatment characteristics that are also useful for the patient himself who can continue the treatment without worries, also considering that patients systematically tend to overestimate the risk of side effects (193).

In conclusion, treatments available for the prevention of fractures from OP usually have a low risk of severe adverse events and the benefits derived from the reduced incidence of fractures, and the consequent reduction in mortality and disability, significantly exceed the risk of side effects.

Conflict of interests: the authors have no conflict of interest to declare.

\section{REFERENCES}

1. Hsia J, Heiss G, Ren H, Allison M, Dolan NC, Greenland P, et al. Calcium/vitamin D supplementation and cardiovascular events. Circulation. 2007; 115: 846-54.

2. LaCroix AZ, Kotchen J, Anderson G, Brzyski R, Cauley JA, Cummings SR, et al. Calcium plus vitamin $\mathrm{D}$ supplementation and mortality in postmenopausal women: the women's health initiative calcium - vitamin D randomized controlled trial. J Gerontol A Biol Sci Med Sci. 2009; 64: 559-67.

3. Al-Delaimy WK, Rimm E, Willett WC, Stampfer MJ, Hu FB. A prospective study of calcium intake from diet and supplements and risk of ischemic heart disease among men. Am J Clin Nutr. 2003; 77: 814-8.

4. Lewis JR, Calver J, Zhu K, Flicker L, Prince RL. Calcium supplementation and the risks of atherosclerotic vascular disease in older women: results of a 5-year RCT and a 4.5year follow-up. J Bone Miner Res. 2011; 26: $35-41$.
5. Prince RL, Devine A, Dhaliwal SS, Dick IM. Effects of calcium supplementation on clinical fracture and bone structure. Arch Intern Med. 2006; 166: 869-75.

6. Avenell A, MacLennan GS, Jenkinson DJ, McPherson GC, McDonald AM, Pant PR, et al. Long-term follow-up for mortality and cancer in a randomized placebo-controlled trial of vitamin $\mathrm{D}(3)$ and/or calcium (RECORD trial). J Clin Endocrinol Metab. 2012; 97: 614-22.

7. Bolland MJ, Barber PA, Doughty RN. Vascular events in healthy older women receiving calcium supplementation: randomised controlled trial. BMJ. 2008; 336: 262-6.

8. Pentti K, Tuppurainen MT, Honkanen R, Sandini L, Kröger H, Alhava E, et al. Use of calcium supplements and the risk of coronary heart disease in 52-62-year-old women: The Kuopio Osteoporosis Risk Factor and Prevention Study. Maturitas. 2009; 63: 73-8.

9. Li K, Kaaks R, Linseisen J, Rohrmann S. Associations of dietary calcium intake and calcium supplementation with myocardial infarction and stroke risk and overall cardiovascular mortality in the Heidelberg cohort of the European Prospective Investigation into Cancer and Nutrition study (EPIC-Heidelberg). Heart. 2012; 98: 920-5.

10. Xiao Q, Murphy RA, Houston DK, Harris TB, Chow WH, Park Y. Dietary and supplemental calcium intake and cardiovascular disease mortality: the National Institutes of Health-AARP Diet and Health Study. JAMA. 2013; 4: 1-8.

11. Bostick RM, Kushi LH, Wu Y, Meyer KA, Sellers TA, Folsom AR. Relation of calcium, vitamin $\mathrm{D}$, and dairy food intake to ischemic heart disease mortality among postmenopausal women. Am J Epidemiol. 1999; 149: 151-61.

12. Mursu J, Robien K, Harnack LJ, Park K, Jacobs DR Jr. Dietary supplements and mortality rate in older women: the Iowa Women's Health Study. Arch Intern Med. 2011; 171: 1625-33.

13. Michaelsson K, Melhus H, Warensjo Lemming E, Wolk A, Byberg L. Long term calcium intake and rates of all cause and cardiovascular mortality: community based prospective longitudinal cohort study. BMJ. 2013; 346: f228.

14. Heaney RP, Kopecky S, Maki KC, Hathcock J, Mackay D, Wallace TC. A review of calcium supplements and cardiovascular disease risk. Adv Nutr. 2012; 3: 763-71.

15. Spence LA, Weaver CM. Calcium intake, vascular calcification, and vascular disease. Nutr Rev. 2013; 71: 15-22.

16. Wang L, Manson JE, Sesso HD. Calcium intake and risk of cardiovascular disease: a review of prospective studies and randomized 
clinical trials. Am J Cardiovasc Drugs. 2012; 12: $105-16$.

17. Miller PD. Vitamin D, calcium, and cardiovascular mortality: a perspective from a plenary lecture given at the annual meeting of the American Association of Clinical Endocrinologists. Endocr Pract. 2011; 17: 798806.

18. Bolland MJ, Avenell A, Baron JA, Grey A, MacLennan GS, Gamble GD, et al. Effect of calcium supplements on risk of myocardial infarction and cardiovascular events: metaanalysis. BMJ. 2010; 341: c3691.

19. SIOMMMS (Società Italiana dell'Osteoporosi, del Metabolismo Minerale e delle Malattie dello Scheletro). Linee Guida per la prevenzione, diagnosi e terapia dell'osteoporosi; 2012. Available from: http://www. siommms.it

20. Kanis JA, McCloskey EV, Johansson H, Cooper C, Rizzoli R, Reginster JY; on behalf of the Scientific Advisory Board of the European Society for Clinical and Economic Aspects of Osteoporosis and Osteoarthritis (ESCEO) and the Committee of Scientific Advisors of the International Osteoporosis Foundation (IOF). European guidance for the diagnosis and management of osteoporosis in postmenopausal women. Osteoporos Int. 2013; 24: 23-57.

21. Watts NB, Bilezikian JP, Camacho PM, Greenspan SL, Harris ST, Hodgson SF, et al. AACE osteoporosis task force. American Association of Clinical Endocrinologists medical guidelines for clinical practice for the diagnosis and treatment of postmenopausal osteoporosis. Endocr Pract. 2010; 16S3: 1-37.

22. Grove ML, Cook D. Doesn't apply to most calcium prescriptions. BMJ. 2010; 341: c5003.

23. Rejnmark L, Avenell A, Masud T, Anderson F, Meyer HE, Sanders KM, et al. Vitamin D with calcium reduces mortality: Patient level pooled analysis of 70,528 patients from eight major vitamin D trials. J Clin Endocrinol Metab. 2012; 97: 2670-81.

24. Bolland MJ, Grey A, Avenell A, Gamble GD, Reid IR. Calcium supplements with or without vitamin D and risk of cardiovascular events: reanalysis of the Women's Health Initiative limited access dataset and metaanalysis. BMJ. 2011; 342: d2040.

25. Peterlik M, Kallay E, Cross HS. Calcium nutrition and extracellular calcium sensing: relevance for the pathogenesis of osteoporosis, cancer and cardiovascular diseases. $\mathrm{Nu}$ trients. 2013; 5: 302-27.

26. West SL, Swan VJ, Jamal SA. Effects of calcium on cardiovascular events in patients with kidney disease and in a healthy population. Clin J Am Soc Nephrol. 2010; 5: S41-7.
27. Samelson EJ, Booth SL, Fox CS, Tucker KL, Wang TJ, Hoffmann U, et al. Calcium intake is not associated with increased coronary artery calcification: the Framingham Study. Am J Clin Nutr. 2012; 96: 1274-80.

28. Nuti R. Calcium supplementation and risk of cardiovascular disease. Clin Cases Miner Bone Metab. 2012; 9: 133-4.

29. Hennekens CH, Barice EJ. Calcium supplements and risk of myocardial infarction: a hypothesis formulated but not yet adequately tested. Am J Med. 2011; 124: 1097-8.

30. Dawson-Hughes B. The heart of the matter. BMJ. 2010; 341: c4993.

31. Curhan GC, Willett WC, Speizer FE, Spiegelman D, Stampfer MJ. Comparison of dietary calcium with supplemental calcium and other nutrients as factors affecting the risk for kidney stones in women. Ann Intern Med. 1997; 126: 497-504.

32. Jackson RD, LaCroix AZ, Gass M, Wallace RB, Robbins J, Lewis CE, et al. Calcium plus vitamin D supplementation and the risk of fractures. N Engl J Med. 2006; 354: 66983.

33. Grant AM, Avenell A, Campbell MK. Oral vitamin D3 and calcium for secondary prevention of low-trauma fractures in elderly people (randomised evaluation of calcium or vitamin D, RECORD): a randomised placebo-controlled trial. Lancet. 2005; 365: 1621-8.

34. Curhan GC, Willett WC, Rimm EB, Stampfer MJ. A prospective study of dietary calcium and other nutrients and the risk of symptomatic kidney stones. N Engl J Med. 1993; 328: 833-8.

35. Taylor EN, Stampfer MJ, Curhan GC. Dietary factors and the risk of incident kidney stones in men: new insights after 14 years of follow-up. J Am Soc Nephrol. 2004; 15 : 3225-32.

36. Curhan GC, Willett WC, Knight EL, Stampfer MJ. Dietary factors and the risk of incident kidney stones in younger women. Nurses' Health Study II. Arch Intern Med. 2004; 164: 885-91.

37. Sorensen MD, Kahn AJ, Reiner AP, Tseng TY, Shikany JM, Wallace RB, et al. Impact of nutritional factors on incident kidney stone formation: a report from the WHI OS. J Urol. 2012; 187: 1645-50.

38. Candelas G, Martinez-Lopez JA, Rosario MP, Carmona L, Loza E. Calcium supplementation and kidney stone risk in osteoporosis: a systematic literature review. Clin Exp Rheumatol. 2012; 30: 954-61.

39. Sanders K, Stuart A, Williamson E, Simpson JA, Kotowicz MA, Young D, et al. Annual high-dose oral vitamin D for falls and fractures in elderly women: a randomised, double-blind, placebo-controlled study. JAMA. 2010; 303: 1815-22. 
40. Smith H, Anderson F, Raphael H, Maslin P, Crozier S, Cooper C. Effect of annual intramuscular vitamin $\mathrm{D}$ on fracture risk in elderly men and women: a population-based, randomized, double-blind, placebo-controlled trial. Rheumatology. 2007; 46: 1852-1857.

41. Sanders K, Nicholson GC, Ebeling PR. Is high dose vitamin D harmful? Calcif Tissue Int. 2013; 92: 191-206.

42. Glendenning $\mathrm{P}$, Zhu K, Inderjeeth $\mathrm{C}$, Howat $\mathrm{P}$, Lewis JR, Prince RL. Effects of threemonthly oral 150,000 IU cholecalciferol supplementation on falls, mobility, and muscle strength in older postmenopausal women: a randomized controlled trial. J Bone Miner Res. 2012; 27: 170-6.

43. Trivedi DP, Doll R, Khaw KT. Effect of four monthly oral vitamin D3 (cholecalciferol) supplementation on fractures and mortality in men and women living in the community: randomised double blind controlled trial. BMJ. 2003; 326: 469-75.

44. Rossini M, Gatti D, Viapiana O, Fracassi E, Idolazzi L, Zanoni S, et al. Short-term effects on bone turnover markers of a single high dose of oral vitamin D. J Clin Endocrinol Metab. 2012; 97: E622-6.

45. Rossini M, Adami S, Viapiana O, Fracassi E, Idolazzi L, Povino MR, et al. Dose-dependent short-term effects of single high doses of oral vitamin $\mathrm{D}(3)$ on bone turnover markers. Calcif Tissue Int. 2012; 9: 365-9.

46. Adami S, Romagnoli E, Carnevale V, Scillitani A, Giusti A, Rossini M, et al. Guidelines on prevention and treatment of vitamin $\mathrm{D}$ deficiency. Reumatismo. 2011; 63: 129-47.

47. Avenell A, Gillespie WJ, Gillespie LD, O'Connell D. Vitamin D and vitamin D analogues for preventing fractures associated with involutional and post-menopausal osteoporosis. Cochrane Database Syst Rev. 2009; CD000227.

48. O’Donnell S, Moher D, Thomas K, Hanley DA, Cranney A. Systematic review of the benefits and harms of calcitriol and alfacalcidol for fractures and falls. J Bone Miner Metab. 2008; 26: 531-42.

49. Peppone LJ, Hebl S, Purnell JQ, Reid ME, Rosier RN, Mustian KM, et al. The efficacy of calcitriol therapy in the management of bone loss and fractures: a qualitative review. Ostoporos Int. 2010; 21: 1133-49.

50. Cashman KD, Seamans KM, Lucey AJ, Stöcklin E, Weber P, Kiely M, et al. Relative effectiveness of oral 25-hydroxyvitamin D3 and vitamin D3 in raising wintertime serum 25-hydroxyvitamin D in older adults. Am J Clin Nutr. 2012; 95: 1350-6.

51. Adami S, Zamberlan N. Adverse effects of bisphosphonates. A comparative review. Drug Saf. 1996; 14: 158-70.

52. Green JR, Rogers M. Pharmacological pro- file of zoledronic acid: a highly potent inhibitor of bone resorption. Drug Dev Res. 2002; 55: 210-24.

53. Papapoulos SE, Cremers SC. Prolonged bisphosphonate release after treatment in children. N Engl J Med 2007; 356: 1075-6.

54. McNicholl DM, Heaney LG. The safety of bisphosphonate use in pre-menopausal women on corticosteroids. Curr Drug Saf. 2010; 5: 182-7.

55. Adami S, Bhalla AK, Dorizzi R, Montesanti F, Rosini S, Salvagno G, et al. The acutephase response after bisphoshonate administration. Calcif Tissue Int. 1987; 41: 326-33.

56. Reid IR, Gamble GD, Mesenbrink P, Lakatos P, Black DM. Characterization of and risk factors for the acute-phase response after zoledronic acid. J Clin Endocrinol Metab. 2010; 95: 4380-7.

57. Miller PD, McClung MR, Macovei L, Stakkestad JA, Luckey M, Bonvoisin B, et al. Monthly oral ibandronate therapy in postmenopausal osteoporosis: 1-year results from the MOBILE study. J Bone Miner Res. 2005; 20: 1315-22.

58. Schweitzer DH, Oostendorp-van de Ruit M, Van der Pluijm G, Lowik CW, Papapoulos SE. Interleukin-6 and the acute phase response during treatment of patients with Paget's disease with the nitrogen-containing bisphosphonate dimethyl-amino-hydroxypropylidene bisphosphonate. J Bone Miner Res. 1995; 10: 956-62.

59. Sauty A, Pecherstorfer M, Zimmer-Roth I, Fioroni P, Juillerat L, Markert M, et al. Interleukin-6 and tumor necrosis factor alpha levels after bisphosphonates treatment in vitro and in patients with malignancy. Bone. 1996; 18: 133-9.

60. Thiebaud D, Sauty A, Burckhardt P, Leuenberger P, Sitzler L, Green JR, et al. An in vitro and in vivo study of cytokines in the acutephase response associated with bisphosphonates. Calcif Tissue Int. 1997; 61: 386-92.

61. Kunzmann V, Bauer E, Wilhelm M. Gamma/ delta T-cell stimulation by pamidronate. $\mathrm{N}$ Engl J Med. 1999; 340: 737-8.

62. Hewitt RE, Lissina A, Green AE, Slay ES, Price DA, Sewell AK. The bisphosphonate acute phase response: rapid and copious production of proinflammatory cytokines by peripheral blood gd $\mathrm{T}$ cells in response to aminobisphosphonates is inhibited by statins. Clin Exp Immunol 2005; 139: 101-11.

63. Roelofs AJ, Jauhiainen M, Monkkonen H, Rogers MJ, Monkkonen J, Thompson K. Peripheral blood monocytes are responsible for gamma delta $\mathrm{T}$ cell activation induced by zoledronic acid through accumulation of IPP/DMAPP. Br J Haematol. 2009; 144: 245-50.

64. Rossini M, Adami S, Viapiana O, Ortolani 
R, Vella A, Fracassi E, et al. Circulating $\gamma \delta$ $\mathrm{T}$ cells and the risk of acute-phase response after zoledronic acid administration. J Bone Miner Res. 2012; 27: 227-30.

65. Rossini M, Adami S, Viapiana O, Fracassi E, Ortolani R, Vella A, et al. Long-term effects of amino-bisphosphonates on circulating gammadelta T cells. Calcif Tissue Int. 2012; 91: 395-399.

66. Rossini M, Adami A, Viapiana O, Tripi G, Zanotti R, Ortolani R, et al. Acute phase response after zoledronic acid is associated with long-term effects on white blood cells. Calcif Tissue Int. 2013. [In press].

67. Wark JD, Bensen W, Recknor C, Ryabitseva O, Chiodo J 3rd, Mesenbrink P, et al. Treatment with acetaminophen/paracetamol or ibuprofen alleviates post-dose symptoms related to intravenous infusion with zoledronic acid 5 mg. Osteoporos Int. 2012; 23: 503-12.

68. Srivastava T, Haney CJ, Alon US. Atorvastatin may have no effect on acute phase reaction in children after intravenous bisphosphonate infusion. J Bone Miner Res. 2009; 24: 334-7.

69. Silverman SL, Kriegman A, Goncalves J, Kianifard F, Carlson T, Leary E. Effect of acetaminophen and fluvastatin on post-dose symptoms following infusion of zoledronic acid. Osteoporos Int. 2011; 22: 2337-45.

70. Thompson K, Rogers MJ. Statins prevent bisphosphonateinduced gamma, delta-T-cell proliferation and activation in vitro. $\mathrm{J}$ Bone Miner Res. 2004; 19: 278-88.

71. Bertoldo F, Pancheri S, Zenari S, Boldini S, Giovanazzi B, Zanatta M, et al. Serum 25-hydroxyvitamin D levels modulate the acute-phase response associated with the first nitrogen-containing bisphosphonate infusion. J Bone Miner Res. 2010; 25: 447-54.

72. Rossini M, Bianchi G, Di Munno O, Giannini S, Minisola S, Sinigaglia L, et al. Determinants of adherence to osteoporosis treatment in clinical practice. Osteoporos Int. 2006; 17: 914-21.

73. de Groen PC, Lubbe DF, Hirsch LJ, Daifotis A, Stephenson W, Freedholm D, et al. Esophagitis associated with the use of alendronate. N Engl J Med. 1996; 335: 1016-21.

74. Cryer B, Miller P, Petruschke RA, Chen E, Geba GP, Papp AE. Upper gastrointestinal tolerability of once weekly alendronate 70 mg with concomitant non-steroidal antiinflammatory drug use. Aliment Pharmacol Ther. 2005; 21: 599-607.

75. Greenspan S, Field-Munves E, Tonino R, Smith M, Petruschke R, Wang L, et al. Tolerability of once-weekly alendronate in patients with osteoporosis: a randomized, double-blind, placebo-controlled study. Mayo Clin Proc. 2002; 77: 1044-52.

76. Eisman JA, Rizzoli R, Roman-Ivorra J, Lip- schitz S, Verbruggen N, Gaines KA, et al. Upper gastrointestinal and overall tolerability of alendronate once weekly in patients with osteoporosis: results of a randomized, double-blind, placebo controlled study. Curr Med Res Opin. 2004; 20: 699-705.

77. Bobba RS, Beattie K, Parkinson B, Kumbhare D, Adachi JD. Tolerability of different dosing regimens of bisphosphonates for the treatment of osteoporosis and malignant bone disease. Drug Saf. 2006; 29: 1133-52.

78. Cadarette SM, Katz JN, Brookhart MA, Sturmer T, Stedman MR, Levin R, et al. Comparative gastrointestinal safety of weekly oral bisphosphonates. Osteoporos Int. 2009; 20: 1735-47.

79. Rosen CJ, Hochberg MC, Bonnick SL, McClung M, Miller P, Broy S, et al. Treatment with once-weekly alendronate $70 \mathrm{mg}$ compared with onceweekly risedronate $35 \mathrm{mg}$ in women with postmenopausal osteoporosis: a randomized double-blind study. J Bone Miner Res. 2005; 20: 141-51.

80. Green J, Czanner G, Reeves G, Watson J, Wise L, Beral V. Oral bisphosphonates and risk of cancer of oesophagus, stomach, and colorectum: case-control analysis within a UK primary care cohort. BMJ. 2010; 341: c4444.

81. Cardwell CR, Abnet CC, Cantwell MM, Murray LJ. Exposure to oral bisphosphonates and risk of esophageal cancer. JAMA. 2010; 304: 657-63.

82. Nguyen DM, Schwartz J, Richardson P, ElSerag HB. Oral bisphosphonate prescriptions and the risk of esophageal adenocarcinoma in patients with Barrett's esophagus. Dig Dis Sci. 2010; 55: 3404-7.

83. Sun K, Liu JM, Sun HX, Lu N, Ning G. Bisphosphonate treatment and risk of esophageal cancer: a meta-analysis of observational studies. Osteoporos Int. 2013; 24: 279-86.

84. Miller PD, Roux C, Boonen S, Barton IP, Dunlap LE, Burgio DE. Safety and efficacy of risedronate in patients with age related reduced renal function as estimated by the Cockcroft and Gault method: a pooled analysis of nine clinical trials. J Bone Miner Res. 2005; 20: 2105-15.

85. Jamal SA, Bauer DC, Ensrud KE, Cauley JA, Hochberg M, Ishani A, Cummings SR. Alendronate treatment in women with normal to severely impaired renal function: an analysis of the fracture intervention trial. $\mathrm{J}$ Bone Miner Res. 2007; 22: 503-8.

86. Toussaint ND, Elder GJ, Kerr PG. Bisphosphonates in chronic kidney disease; balancing potential benefits and adverse effects on bone and soft tissue. Clin J Am Soc Nephrol. 2009; 4: 221-33.

87. Fan SL, Almond MK, Ball E, Evans K, Cunningham J. Pamidronate therapy as preven- 
tion of bone loss following renal transplantation. Kidney Int. 2000; 57: 684-90.

88. Coco M, Glicklich D, Faugere MC, Burris L, Bognar I, Durkin P, et al. Prevention of bone loss in renal transplant recipients: a prospective, randomized trial of intravenous pamidronate. J Am Soc Nephrol. 2003; 14: 2669-76.

89. Palmer SC, McGregor DO, Strippoli GF. Interventions for preventing bone disease in kidney transplant recipients. Cochrane Database Syst Rev. 2007; CD005015.

90. Bounameaux HM, Schifferli J, Montani JP, Jung A, Chatelanat F. Renal failure associated with intravenous diphosphonates. Lancet. 1983; 1: 471.

91. Miller PD. The kidney and bisphosphonates. Bone. 2011; 49: 77-81.

92. Bock O, Boerst H, Thomasius FE, Degner C, Stephan-Oelkers M, Valentine SM, et al. Common musculoskeletal adverse effects of oral treatment with once weekly alendronate and risedronate in patients with osteoporosis and ways for their prevention. J Musculoskelet Neuronal Interact. 2007; 7: 144-8.

93. Black DM, Delmas PD, Eastell R, Reid IR, Boonen S, Cauley JA, et al. Once-yearly zoledronic acid for treatment of postmenopausal osteoporosis. N Engl J Med. 2007; 356: 1809-22.

94. Caplan L, Pittman CB, Zeringue AL, Scherrer JF, Wehmeier KR, Cunningham FE, et al. An observational study of musculoskeletal pain among patients receiving bisphosphonate therapy. Mayo Clin Proc. 2010; 85: 3418.

95. Rey J, Daumen-Legre V, Pham T, Bernard P, Dahan L, Acquaviva PC, et al. Uveitis, an under-recognized adverse effect of pamidronate. Case report and literature review. Joint Bone Spine. 2000; 67: 337-40.

96. Malik AR, Campbell SH, Toma NM. Bilateral acute anterior uveitis after alendronate. Br J Ophthalmol. 2002; 86: 1443.

97. Durnian JM, Olujohungbe A, Kyle G. Bilateral acute uveitis and conjunctivitis after zoledronic acid therapy. Eye (Lond) 2005; 19: 221-2.

98. Fietta P, Manganelli P, Lodigiani L. Clodronate induced uveitis. Ann Rheum Dis. 2003; 62: 378 .

99. Fraunfelder FW, Fraunfelder FT, Jensvold B. Scleritis and other ocular side effects associated with pamidronate disodium. Am J Ophthalmol. 2003; 135: 219-22.

100. Brinkmeier T, Kugler K, Lepoittevin JP, Frosch PJ. Adverse cutaneous drug reaction to alendronate. Contact Dermatitis. 2007; 57: 123-5.

101. Krasagakis K, Kruger-Krasagakis S, Ioannidou D, Tosca A. Chronic erosive and ulcerative oral lesions caused by incorrect administration of alendronate. J Am Acad Dermatol. 2004; 50: 651-2.

102. Yanik B, Turkay C, Atalar H. Hepatotoxicity induced by alendronate therapy. Osteoporos Int. 2007; 18: 829-31.

103. Phillips MB. Risedronate-induced hepatitis. Am J Med 2007; 120: e1-2.

104. Varma R, Aronow WS, Basis Y, Singh T, Kalapatapu K, Weiss MB, et al. Relation of bone mineral density to frequency of coronary heart disease. Am J Cardiol 2008; 101: 1103-4.

105. Choi SH, An JH, Lim S, Koo BK, Park SE, Chang HJ, et al. Lower bone mineral density is associated with higher coronary calcification and coronary plaque burdens by multidetector row coronary computed tomography in pre- and postmenopausal women. Clin Endocrinol (Oxf). 2009; 71: 644-51.

106. Black DM, Delmas PD, Eastell R, Reid IR, Boonen S, Cauley JA, et al. HORIZON Pivotal Fracture Trial. Once-yearly zoledronic acid for treatment of postmenopausal osteoporosis. N Engl J Med. 2007; 356: 1809-22.

107. Lyles KW, Colon-Emeric CS, Magaziner JS, Adachi JD, Pieper CF, Mautalen C, et al. Zoledronic acid and clinical fractures and mortality after hip fracture. N Engl J Med 2007; 357: 1799-809.

108. Cummings SR, Schwartz AV, Black DM. Alendronate and atrial fibrillation. N Engl J Med. 2007; 356: 1895-6.

109. Karam R, Camm J, McClung M. Yearly zoledronic acid in postmenopausal osteoporosis. N Engl J Med. 2007; 357: 712-3, author reply 714-5.

110. Lewiecki EM, Cooper C, Thompson E, Hartl F, Mehta D, Papapoulos SE. Ibandronate does not increase risk of atrial fibrillation in analysis of pivotal clinical trials. Int J Clin Pract 2010; 64: 821-6.

111. Colón-Emeric CS, Mesenbrink P, Lyles KW, Pieper CF, Boonen S, Delmas P, et al. Potential mediators of the mortality reduction with zoledronic acid after hip fracture. J Bone Miner Res. 2010; 25: 91-7.

112. Wolfe F, Bolster MB, O'Connor CM, Michaud K, Lyles KW, Colón-Emeric CS. Bisphosphonate use is associated with reduced risk of myocardial infarction in patients with rheumatoid arthritis. J Bone Miner Res. 2013; 28: 984-91.

113. Khosla S, Burr D, Cauley J, Dempster DW, Ebeling PR, Felsenberg D, et al. Bisphosphonates-associated osteonecrosis of the jaw: report of a task force of the American Society for bone and mineral research. ASBMR Task Force on Bisphosphonate-Associated ONJ. J Bone Miner Res. 2007; 22: 1479-91.

114. Ruggiero SL, Dodson TB, Assael LA. Task force on bisphosphonate-related osteonecrosis of the jaws, American Association of Oral 
and Maxillofacial Surgeons. American Association of Oral and Maxillofacial Surgeons position paper on bisphosphonate-related osteonecrosis of the jaw - 2009 update. Aust Endod J. 2009; 35: 119-30.

115. Bedogni A, Fusco V, Agrillo A, Campisi G. Learning from experience. Proposal of a refined definition and staging system for bisphosphonate-related osteonecrosis of the jaw (BRONJ). Oral Dis. 2012; 18: 621-3.

116. Bertoldo F, Santini D, Lo Cascio VL. Bisphosphonates and osteomyelitis of the jaw: a pathogenic puzzle. Nat Clin Pract Oncol. 2007; 4: 711-21.

117. Kyrgidis A, Vahtsevanos K, Koloutsos G. Bisphosphonate-related osteonecrosis of the jaws: a case-control study of risk factors in breast cancer patients. J Clin Oncol. 2008; 26: 4634-8.

118. Filleul O, Crompot E, Saussez S. Bisphosphonate-induced osteonecrosis of the jaw: a review of 2,400 patient cases. J Cancer Res Clin Oncol. 2010; 136: 1117-24.

119. Yarom N, Yahalom R, Shoshani Y, Hamed W, Regev E, Elad S. Osteonecrosis of the jaw induced by orally administered bisphosphonates: incidence, clinical features, predisposing factors and treatment outcome. Osteoporos Int. 2007; 18: 1363-70.

120. Reid IR, Cornish J. Epidemiology and pathogenesis of osteonecrosis of the jaw. Nat Rev Rheumatol. 2011; 8: 90-6.

121. Mavrokokki T, Cheng A, Stein B, Goss A. The nature and incidence of bisphosphonates associated osteonecrosis of the jaws in Australia. J Oral Maxilofac Surg. 2007; 65: 415-23.

122. Solomon DH, Mercer E, Woo SB, Avorn J, Schneeweiss S, Treister N. Defining the epidemiology of bisphosphonate-associated osteonecrosis of the jaw: prior work and current challenges. Osteoporos Int. 2013; 24: 237-44.

123. Felsenberg D. Osteonecrosis of the jaw-a potential adverse effect of bisphosphonate treatment. Nat Clin Pract Endocrinol Metab. 2006; 2: 662-3.

124. Bedogni A, Campisi G, Fusco V, Agrillo A; A nome di SICMF e SIPMO. Raccomandazioni clino-terapeutiche su ostenecrosi dei mascellari associata a bisfosfonati e sua prevenzione. Marzo 2013. Padova: CLEUP Ed; 2013.

125. Shane E, Burr D, Ebeling PR, Abrahamsen B, Adler RA, Brown TD, et al. Atypical subtrochanteric and diaphyseal femoral fractures: report of a task force of the American Society for Bone and Mineral Research. J Bone Miner Res. 2010; 25: 2267-94.

126. Giusti A, Hamdy NA, Papapoulos SE. Atypical fractures of the femur and bisphosphonate therapy: a systematic review of case/ case series studies. Bone. 2010; 47: 169-80.
127. Whyte MP. Atypical femoral fractures, bisphosphonates, and adult hypophosphatasia. J Bone Miner Res. 2009; 24: 1132-4.

128. Paparodis R, Buehring B, Pelley E, Binkley N. A case of an unusual subtrochanteric fracture in a patient receiving denosumab. Endocr Pract. 2013; 21: 1-17.

129. Lippuner K, Roux C, Bone HG, Zapalowski C, Minisola S, Franek E, et al. Denosumab treatment of postmenopausal women with osteoporosis for 7 years: clinical fracture results from the first 4 years of the FREEDOM extension. Osteoporos Int. 2013; 24: S39-40.

130. Girgis CM, Sher D, Seibel MJ. Atypical femoral fractures and bisphosphonate use. $\mathrm{N}$ Engl J Med. 2010; 362: 1848-9.

131. Giusti A, Hamdy NA, Dekkers OM, Ramautar SR, Dijkstra S, Papapoulos SE. Atypical fractures and bisphosphonate therapy: a cohort study of patients with femoral fracture with radiographic adjudication of fracture site and features. Bone. 2011; 48: 966-71.

132. Schilcher J, Michaelsson K, Aspenberg P. Bisphosphonate use and atypical fractures of the femoral shaft. N Engl J Med. 2011; 364: 1728-37.

133. Girgis CM, Seibel MJ. Population and treatment-based incidence estimates of atypical fractures. Med J Aust. 2011; 194: 666.

134. Dell RM, Adams AL, Greene DF, Funahashi TT, Silverman SL, Eisemon EO, et al. Incidence of atypical nontraumatic diaphyseal fractures of the femur. J Bone Miner Res. 2012; 27: 2544-50.

135. Thompson RN, Phillips JR, McCauley SH, Elliott JR, Moran CG. Atypical femoral fractures and bisphosphonate treatment: experience in two large United Kingdom teaching hospitals. J Bone Joint Surg Br. 2012; 94 : 385-90.

136. Warren C, Gilchrist N, Coates M, Frampton C, Helmore J, McKie J, et al. Atypical subtrochanteric fractures, bisphosphonates, blinded radiological review. ANZ J Surg. 2012; 82: 908-12.

137. Meier RP, Perneger TV, Stern R, Rizzoli R, Peter RE. Increasing occurrence of atypical femoral fractures associated with bisphosphonate use. Arch Intern Med. 2012; 172: 930-6.

138. Feldstein AC, Black D, Perrin N, Rosales AG, Friess D, Boardman D, et al. Incidence and demography of femur fractures with and without atypical features. J Bone Miner Res. 2012; 27: 977-86.

139. Beaudouin-Bazire C, Dalmas N, Bourgeois J, Babinet A, Anract P, Chantelot C, et al. Real frequency of ordinary and atypical sub-trochanteric and diaphyseal fractures in France based on X-rays and medical file analysis. Joint Bone Spine. 2013; 80: 201-5.

140. Tamminen IS, Yli-Kyyny $\mathrm{T}$, Isaksson $\mathrm{H}$, 
Turunen MJ, Tong X, Jurvelin JS, et al. Incidence and bone biopsy findings of atypical femoral fractures. J Bone Miner Metab. 2013. [Epub ahead of print].

141. Gedmintas L, Solomon DH, Kim SC. Bisphosphonates and risk of subtrochanteric, femoral shaft, and atypical femur fracture: a systematic review and meta-analysis. J Bone Miner Res. 2013. [Epub ahead of print].

142. Schilcher J, Koeppen V, Ranstam J, Skripitz R, Michaelsson K, Aspenberg P. Atypical femoral fractures are a separate entity, characterized by highly specific radiographic features. A comparison of 59 cases and 218 controls. Bone. 2013; 52: 389-92.

143. Lenart BA, Neviaser AS, Lyman S, Chang CC, Edobor-Osula F, Steele B, et al. Association of low-energy femoral fractures with prolonged bisphosphonate use: a case control study. Osteoporos Int. 2009; 20: 1353-62.

144. Shkolnikova J, Flynn J, Choong P. Burden of bisphosphonate-associated femoral fractures. ANZ J Surg. 2013; 83: 175-81.

145. Lo JC, Huang SY, Lee GA, Khandewal S, Provus J, Ettinger B, et al. Clinical correlates of atypical femoral fracture. Bone. 2012; 51: 181-4.

146. Erviti J, Alonso A, Oliva B, Gorricho J, Lopez A, Timoner J, et al. Oral bisphosphonates are associated with increased risk of subtrochanteric and diaphyseal fractures in elderly women: a nested case-control study. BMJ Open. 2013; 3.

147. Nieves JW, Cosman F. Atypical subtrochanteric and femoral shaft fractures and possible association with bisphosphonates. Curr Osteoporos Rep. 2010; 8: 34-9.

148. Compston J. Pathophysiology of atypical femoral fractures and osteonecrosis of the jaw. Osteoporos Int. 2011; 22: 2951-61.

149. Odvina CV, Levy S, Rao S, Zerwekh JE, Rao DS. Unusual mid-shaft fractures during long-term bisphosphonate therapy. Clin Endocrinol (Oxf). 2010; 72: 161-8.

150. Odvina CV, Zerwekh JE, Rao DS, Maalouf N, Gottschalk FA, Pak CY. Severely suppressed bone turnover: a potential complication of alendronate therapy. J Clin Endocrinol Metab. 2005; 90: 1294-301.

151. Black DM, Kelly MP, Genant HK, Palermo L, Eastell R, Bucci-Rechtweg C, et al. Bisphosphonates and fractures of the subtrochanteric or diaphyseal femur. $\mathrm{N}$ Engl $\mathrm{J}$ Med. 2010; 362: 1761-71.

152. Watts NB, Diab DL. Long-term use of bisphosphonates in osteoporosis. J Clin Endocrinol Metab. 2010; 95: 1555-65.

153. Laster AJ, Tanner SB. Duration of treatment in postmenopausal osteoporosis: how long to treat and what are the consequences of cessation of treatment? Rheum Dis Clin North Am. 2011; 37: 323-36.
154. Miller PD, Derman RJ. What is the best balance of benefits and risks among anti-resorptive therapies for postmenopausal osteoporosis? Osteoporos Int. 2010; 21: 1793-802.

155. European Medicines Agency. Strontium Ranelate. Summary of product characteristic, 3 June 2010. London: European Medicines Agency; 2010.

156. Breart G, Cooper C, Meyer O, Speirs C, Deltour N, Reginster JY. Osteoporosis and venous thromboembolism: a retrospective cohort study in the UK General Practice Research Database. Osteoporos Int. 2010; 21: 1181-7.

157. Osborne V, Layton D, Perrio M, Wilton L, Shakir SA. Incidence of venous thromboembolism in users of strontium ranelate: an analysis of data from a prescription-event monitoring study in England. Drug Saf. 2010; 33: 579-91.

158. Breart G, Jakob FJ, Palacios S, Audran M, Brandi ML, Broll $\mathrm{H}$, et al. New interim analysis of a retrospective cohort study of patients treated with strontium ranelate. Osteoporosis Int. 2010; 21: S166.

159. Audran M, Jakob FJ, Palacios S, Brandi ML, Bröll H, Hamdy NA, et al. A large prospective European cohort study of patients treated with strontium ranelate and followed up over 3 years. Rheumatol Int. 2013. [Epub ahead of print].

160. European Medicines Agency. Questions and answers on the review of Protelos and Osseor (strontium ranelate), 15 March 2012. London: European Medicines Agency; 2012.

161. Jonville-Béra AP, Crickx B, Aaron L, Hartingh I, Autret-Leca E. Strontium ranelateinduced DRESS syndrome: first two case reports. Allergy. 2009; 64: 658-9.

162. Lee HY, Lie D, Lim KS, Thirumoorthy T, Pang SM. Strontium ranelate-induced toxic epidermal necrolysis in a patient with postmenopausal osteoporosis. Osteoporos Int. 2009; 20: 161-2.

163. Pernicova I, Middleton ET, Aye M. Rash, strontium ranelate and DRESS syndrome put into perspective. European Medicine Agency on the alert. Osteoporos Int. 2008; 19: 18112.

164. Musette P, Brandi ML, Cacoub P, Kaufman JM, Rizzoli R, Reginster JY. Treatment of osteoporosis: recognizing and managing cutaneous adverse reactions and drug-induced hypersensitivity. Osteoporos Int. 2010; 21: 723-32.

165. Body JJ, Bergmann P, Boonen S, Devogelaer JP, Gielen E, Goemaere S, et al. Extraskeletal benefits and risks of calcium, vitamin D and anti-osteoporosis medications. Osteoprosis Int. 2012; 23: S1-23.

166. European Medicines Agency. Reccomandation to restrict the use of Protelos/Osseor / 
strontium ranelate. CHMP confirms reccomandation from the PRAC, 25 April 2013. London: European Medicines Agency; 2013.

167. Determinazione AIFA n. 800 del 13 Settembre 2013; G.U. n. 22019 Settembre 2013.

168. Writing Group for the Women's Health Initiative Investigators. Risks and benefits of estrogen plus progestin in healthy postmenopausal women: principal results from the Women's Health Initiative Randomized Controlled Trial. JAMA. 2002; 288: 321-33.

169. Ettinger B, Black DM, Mitlak BH, Knickerbocker RK, Nickelsen T, Genant HK, et al. Reduction of vertebral fracture risk in postmenopausal women with osteoporosis treated with raloxifene: results from a 3-year randomized clinical trial. JAMA. 1999; 282: 637-45.

170. Grady D, Ettinger B, Moscarelli E, Plouffe L Jr, Sarkar S, Ciaccia A, et al. Safety and adverse effects associated with raloxifene: multiple outcomes of raloxifene evaluation. Obstet Gynecol. 2004; 104: 837-44.

171. Grady D, Wenger NK, Herrington D, Khan S, Furberg C, Hunninghake D, et al. Postmenopausal hormone therapy increases risk for venous thromboembolic disease. The Heart and Estrogen/progestin Replacement Study. Ann Intern Med. 2000; 132: 689-96.

172. Adomaityte J, Farooq M, Qayyum R. Effect of raloxifene therapy on venous thromboembolism in postmenopausal women. A metaanalysis. Thromb Haemost. 2008; 99: 33842.

173. Barrett-Connor E, Mosca L, Collins P, Geiger MJ, Grady D, Kornitzer M, et al. Effects of raloxifene on cardiovascular events and breast cancer in postmenopausal women. $\mathrm{N}$ Engl J Med. 2006; 355: 125-37.

174. Mosca L, Grady D, Barrett-Connor E, Collins $\mathrm{P}$, Wenger N, Abramson BL, et al. Effect of raloxifene on stroke and venous thromboembolism according to subgroups in postmenopausal women at increased risk of coronary heart disease. Stroke 2009; 40: 147-55.

175. Duvernoy CS, Yeo AA, Wong M, Cox DA, Kim HM. Antiplatelet therapy use and the risk of venous thromboembolic events in the Raloxifene Use for the Heart (RUTH) trial. J Womens Health. 2010; 19: 1459-65.

176. Grady D, Cauley JA, Stock JL, Cox DA, Mitlak BH, Song J, et al. Effect of Raloxifene on all-cause mortality. Am J Med. 2010; 123: 469. e1-469.e7.

177. Sarkar S, Mitlak BH, Wong M, Stock JL, Black DM, Harper KD. Relationships between bone mineral density and incident vertebral fracture risk with raloxifene therapy. $\mathrm{J}$ Bone Miner Res. 2002; 17: 1-10.

178. Davies GC, Huster WJ, Lu Y, Plouffe L Jr, Lakshmanan M. Adverse events reported by postmenopausal women in controlled trials with raloxifene. Obstet Gynecol. 1999; 93: 558-65.

179. Silverman SL, Christiansen C, Genant HK, Vukicevic S, Zanchetta JR, de Villiers TJ, et al. Efficacy of bazedoxifene in reducing new vertebral fracture risk in postmenopausal women with osteoporosis: results from a 3-year, randomized, placebo-, and activecontrolled clinical trial. J Bone Miner Res. 2008; 23: 1923-34.

180. Christiansen C, Chesnut $\mathrm{CH}$ 3rd, Adachi JD, Brown JP, Fernandes CE, Kung AW, et al. Safety of bazedoxifene in a randomized, double-blind, placebo- and active-controlled Phase 3 study of postmenopausal women with osteoporosis. BMC Musculoskelet Disord. 2010; 11: 130.

181. Silverman SL, Chines AA, Kendler DL, Kung AW, Teglbjærg CS, Felsenberg D, et al. Sustained efficacy and safety of bazedoxifene in preventing fractures in postmenopausal women with osteoporosis: results of a 5-year, randomized, placebo-controlled study. Osteoporos Int. 2012; 23: 351-63.

182. Palacios S, Silverman S, Levine AB, Jaufman JM, Brown JP, de Cicco Nardone F, et al. Long-term efficacy and safety of Bazedoxifene in postmenopausal women with osteoporosis: results of a 7-year, randomized, placebo-controlled study. Presented at the 13th International Menopause Society World Congress, 8-11 June 2011, Rome, Italy [Abs 973].

183. Malan J, Etnger K, Naumann E, Beirne OR. The relationship of denosumanb pharmacology and ostenecrosis of the jaw. Oral Surg Oral Med Oral Pathol Oral Radiol. 2012; 114: 671-6.

184. Papapoulos S, Chapurlat R, Libanati C, Brandi ML, Brown JP, Czerwin'ski E, et al. Five years of denosumab exposure in women with postmenopausal osteoporosis: results from the first two years of the FREEDOM extension. J Bone Miner Res. 2012; 27: 694701.

185. Saad F, Brown JE, Van Poznak C, Ibrahim T, Stemmer SM, Stopeck AT, et al. Incidence, risk factors, and outcomes of osteonecrosis of the jaw: Integrated analysis from three blinded active-controlled phase III trials in cancer patients with bone metastases. Ann Oncol. 2012; 23: 1341-7.

186. Giusti A, Hamdy NA, Papapoulos SE. Atypical fractures of the femur and bisphosphonate therapy: a systematic review of case/ case series studies. Bone. 2010; 47: 169-80.

187. Lippuner K, Roux C, Bone HG, Zapalowski C, Minisola S, Franek E, et al. Denosumab treatment of postmenopausal women with osteoporosis for 7 years: clinical fracture results from the first 4 years of the FREE- 
DOM extension. Osteoporos Int. 2013; 24: S39-40.

188. Paparodis R, Buehring B, Pelley E, Binkley $N$. A case of an unusual subtrochanteric fracture in a patient receiving Denosumab. Endocr Pract. 2013; 21: 1-17.

189. Cummings SR, San Martin J, McClung MR, Siris ES, Eastell R, Reid IR, et al. FREEDOM Trial. Denosumab for prevention of fractures in postmenopausal women with osteoporosis. N Engl J Med. 2009; 361: 756-65.

190. Medicines and Healthcare Products Regulatory Agency. Denosumab $60 \mathrm{mg}$ (Prolia): rare cases of atypical femoral fracture with long-term use. Drug Safety Update February 2013; 6:A1. Available from: http://www.
mhra.gov.uk/Safetyinformation/DrugSafetyUpdate/CON239411.

191. Neer RM, Arnaud CD, Zanchetta JR, Prince R, Gaich GA, Reginster JY, et al. Effect of parathyroid hormone (1-34) on fractures and bone mineral density in postmenopausal women with osteoporosis. N Engl J Med. 2001; 344: 1434-41.

192. Hodsman AB, Bauer DC, Dempster DW, Dian L, Hanley DA, Harris ST, et al. Parathyroid hormone and teriparatide for the treatment of osteoporosis: a review of the evidence and suggested guidelines for its use. Endocr Rev. 2005; 26: 688-703.

193. Berry DC, Knapp P, Raynor DK. Provision of information about drug side-effects to patients. Lancet. 2002; 359: 853-4. 